\title{
Особенности представдений об успехе как фактор социализации современных студентов
}

\author{
Хава Х. Тамасханова \\ Ингушский государственный университет, г. Назрань, Российская Федерация. \\ E-mail: khava.tamaskhanova@mail.ru
}

\section{Аннотация}

Во Введении преАставлена аргументация актуальности исследования. Анализируются современные подходы в исслеАовании роли преАставлений об успехе в регуляции активности стулентов. Рассматриваются фокторы макросоциального, микросоциального и субъективного уровня. Анализируются субъективные факторы, способствующие Аостижению успеха и конструктивной социализации в стуленческом возрасте. Описываются направления развития преалаптивной активности стулента. Аана характеристика роли преАставлений о способах развития преалаптивности субъекта в повышении успешности в условиях неопределённости. Новизна исслеАования заключается в выявлении и описании особенностей содержания представлений об успехе у современных стулентов в условиях неопределенности. Впервые описывается взаимосвязь порторолио стуАентов и особенностей их представлений об успехе. В работе описаны векторы влияния таких преАставлений на выбор моАели социализации и роль преалаптации в ней. Разде^ Методы описывает метолики, использованные в исследовании. Это Анкета «Аетерминанты успеха и способы его Аостижения» (Т.Н. Щербакова, О. Киреев); Тест-опросник «Потребность в Аостижении» (Ю.М. Орлов, В.И. Шуркин, А.П. Орлова); Анализ солержания портфолио стулентов. В разделе Результаты показана роль представлений о возможностях Аостижения успеха в молелировании конструктивной инАивиАуальной траектории продвижения в чебно-продрессиональной деятельности. Анализируется солержание представ^ений о фракторах и проекциях успеха у студентов с разным уровнем алаптации в вузе, полтвержлённым портфолио. Эмпирически выявлены и систематизированы характеристики Аетерминации Аостижения успеха у стулентов в условиях неопреАеленности. В ОбсужАении результатов преАставлено описание и интерпретация результатов эмпирического исслеАования, которые Аоказывают значение представлений студентов о фракторах, Аетерминирующих успех в регуляции социального поведения и учебно-продессиональной деятельности. Показана роль развития солержания преАставлений о мотивации роста и успешности Аичности в опреАелении продуктивности повеАения студентов в условиях неопреАеленности современной социальной ситуации развития. В Заключении полчеркивается наличие 
связи преАставлений студентов о составляющих Аетерминации успеха и реальной успешности ^ичности. Уровень осмысления факторов успеха способствует формированию алекватных современным требованиям молелей социализации мичности, ее продуктивности, жизнестойкости и конкурентоспособности. Показана модель программы психологического обеспечения оптимизации адаптации студентов в вузе в современных условиях неопределенности.

\title{
КАючевые слова
}

субъективные представления, успех, социализация, студент, адаптация, риски, трансорормация

\section{Для цитирования}

Тамасханова Х.Х. Особенности представлений об успехе как фактор социализации современных студентов // Инновационная наука: психология, педагогика, дефектология. 2021. Т. 4, № 2. С. 48-61. doi: https://doi. org/10.23947/2658-7165-2021-4-2-48-61

\section{Features of the idea of success as a factor in the socialization of modern students}

\author{
Khava H. Tamaskhanova \\ Ingush State University, Nazran, Russian Federation. \\ E-mail: khava.tamaskhanova@mail.ru
}

\begin{abstract}
The introduction provides an argumentation for the relevance of the study. The article analyzes modern approaches to the study of the role of ideas about success in the regulation of students' activities. Factors of macrosocial, microsocial, and subjective levels are considered. The subjective factors contributing to the achievement of success and constructive socialization at the student age are analyzed. Described directions of development of student's preadaptive activity. The article gives the characterization of the role of ideas about developing the subject's pre-adaptability in increasing success in conditions of uncertainty. The novelty of the research lies in the identification and description of the peculiarities of the content of ideas about success among modern students in conditions of uncertainty. For the first time, the article describes the relationship between the portfolio of students and the characteristics of their ideas about success. The article describes the vectors of the influence of such representations on the socialization model choice and the role of preadaptation in it. The Methods section describes the techniques used in the research. This is the Questionnaire "Determinants of Success and Ways to Achieve It" (by T. N. Shcherbakova
\end{abstract}


ПСИХОЛОГИЯ

and O. Kireev); "Need for achievement" test (by Yu. M. Orlov, and V. I. Shurkin, L. P. Orlova); Analysis of the students' portfolio. The Results section shows the role of ideas about the possibilities of achieving success in modeling a constructive individual trajectory of advancement in educational and professional activities. The content of ideas about the factors and projections of success among students with different levels of adaptation in the university, confirmed by a portfolio, is analyzed. Empirically revealed and systematized the characteristics of determination of success among students in conditions of uncertainty. Discussion of the results presents a description and interpretation of the results of empirical research. It proves the importance of students' ideas about the factors that determine success in the regulation of social behavior and educational and professional activities. The role of the development of the content of ideas about the motivation of growth and the success of the individual in determining the productivity of students' behavior in the context of the uncertainty of the modern social situation of development is shown. The Conclusion emphasizes the presence of a connection between students' ideas about the components of the determination of success and the real success of an individual. The level of understanding of success factors contributes to the formation of models of personality, socialization, adequate to modern requirements, productivity, resilience, and competitiveness. The model of the program of psychological support for the optimization of adaptation of students at the university in modern conditions of uncertainty is shown.

\section{Keywords}

subjective perceptions, success, socialization, student, adaptation, risks, transformation

\section{For citation}

Tamaskhanova, Kh. H. (2021). Features of the idea of success as a factor in the socialization of modern students. Innovative Science: psychology, pedagogy, defectology, 4(2), 48-61. doi: https://doi.org/10.23947/2658-7165-2021-4-2-48-61

\section{Введение}

Трансформации современной социореальности провоцируют сосуществование разнообразных моделей социализации и раздичных жизненных векторов развития в контексте жизненного пути. Сегодня, в условиях кредитно-модульной системы профессионального образования возрастает ценность индивидуадьной образовательной траектории, позволяющей будущему специалисту персонализироваться в пространстве вуза. Востребованным сегодня является специалист с активной жизненной позицией, способный к мобильным, своевременным и продуктивным трансформациям. В данном контексте особое значение приобретает фокусировка исследований на психологических факторах, внешних и внутренних ресурсах, механизмах и способов, позволяющих развивать не только 
способность адаптироваться к быстроменяющимся условиям жизнедеятельности, но и формировать преадаптивные способности как видение векторов развития в будущем и готовность к изменениям, обеспечивающим эффективность в ситуации выбора.

В современной психологии акцентируется внимание на значении понимания особенностей актуальной социальной ситуации развития субъекта определенного возраста, так как его трансформации социально и культурно обусловлены. В рамках субъектно-деятельностного подхода подчеркивается идея о том, что развивающийся субъект, действуя и творчески самосовершенствуясь, создает себя как субъекта, свой имидж и индивидуальную траекторию продвижения.

Сегодня предметом исследования в психологии все чаще становятся вопросы продуктивных стратегий поведения дичности в стремительно изменяющемся мире и условий жизнедеятельности в ситуации множественности альтернатив социализации и стилей жизни. В приоритете научных изысканий оказывается тема становления способности к преадаптации в контексте модернизации профессионального образования (Асмолов, Шехтер, Черноризов, 2017).

Достаточно перспективным в направлении определения предикторов успешной адаптации современных студентов является исследование возможностей формирования компетенций дичности в сфере принятия результативных решений в ситуации неопределенности с учетом адекватности индивидуальных когнитивных схем познания и современной реальности (Петровский, 2018; Abakumova, Zvezdina, Grishina, Zvezdina, Dyakova, 2020).

Дия эффективной жизнедеятельности в современном мире большое значение имеет выраженность мотивации активности, совершаемой субъектом в ракурсе жизненной стратегии, устремлений личности (Никоненко, 2018), степень устойчивости дичности, целенаправленности и продуктивности поведения в ситуациях неопределенности (Дубровина, Домитрак, Фирсова, 2020; Звонова, Мельников, 2020). В современной социализации будущего специалиста в системе профессиональной подготовки важно не только развитие когнитивной компетентности, но и сформированность регуляторных процессов, способности самоконтроля и самокоррекции. С точки зрения отечественных психологов, значимой проблемой развития студента как субъекта учебно-профессиональной деятельности в период социализации в вузе сегодня является поиск психологически целесообразных технологий индивидуализации и персонификации образовательных траекторий в контексте дистанционного обучения ситуации в системе профессионализации.

В современной психологии появляются новые термины, отражающие новые тенденции требований к уровню адаптивности субъекта в условиях высокой динамичности инноваций и неопределённости, одним из них явдяется понятие 
ПСИХОЛОГИЯ

«преадаптация», разрабатываемое сегодня А. Г. Асмодовым и группой психологов. Идея предварительной адаптации в психологических исследованиях относится к проработке возможности освоения развивающимся субъектом новых функций, способных обеспечивать его эффективность и благополучие завтра (Асмолов и др., 2017). Термин «преадаптация» сегодня объясняет, во многом, тенденцию основных содержательных трансформаций системы высшего профессионального образования.

Здесь особую значимость приобретает нахождение результативных способов формирования адекватных представлений молодых людей о сущности, векторах и механизмах преадаптации и субъективных предикторах успешности студента как субъекта настоящей и будущей учебно-профессиональной деятельности, его личностного роста и конкурентоспособности. Субъективные представления задают формат внутренней и внешней активности студентов, тем самым определяя построение индивидуальной траектории продвижения в обучении и приобретении социального опыта. Ценность разработки вопросов определения детерминант успешной адаптации будущих специалистов в ситуации нарастающих инноваций определяется необходимостью надичия следующих позиций в психологической организации студентов: высокой толерантности к стрессу и энтропии; компетентности, должного уровня психологической готовности проявлять критичность мышления и ответственность при решении проблем, выраженности способностей к быстрому и качественному освоению новых технологий; высокого уровня мотивации достижений; выраженности дичностного смысла продвижения в профессиональном и социальном пространстве (Звездина, 2015; Соколович, 2020).

В настоящее время в психологических исследованиях делается акцент на значимости адекватности содержания, структурированности и развернутости субъективных представлений для развивающейся дичности об успехе и механизмах его достижения. Именно эти представления становятся действенными мотиваторами продуктивной активности и личностного роста студентов на этапе социадизации в контексте новых форматов учебно-профессионадьной деятельности в ситуации повышенной динамичности и неопределенности современной ситуации развития будущих специалистов. В психологии неоднократно отечественные и зарубежные ученые доказывади особую сензитивность периода студенчества к решению «задач на смысл», ценностно-смысловых выборов, формированию продуктивной направленности инициативных действий, что оказывает влияние на весь жизненный путь и стратегию жизни (Абакумова, Кагермазова, 2008; Зинченко, Дорожкин, Зеер, 2020).

По-существу, само желание быть успешным и социализированным, получать позитивное подкрепление в «социальных зеркалах», как доказывают исследования Т. Н. Щербаковой, определяются ценностными ориентациями дичности будущего 
специалиста на компетентность и дичностный рост, в которых находят отражение и субъективные представления. Эти психологические образования «задают планку» продуктивной активности, качество самоэффективности, способствуют развитию способности эффективно решать проблемы и моделировать условия жизни и деятельности, соответствующие запросу современности. На уровне индивидуального субъекта учебно-профессиональной деятельности представления об успехе играют в процессе социализации инициирующую, организующую и регулирующую функцию (Shcherbakova, Misirov, Akobyan, Zhitnaya, 2019).

В психологии доказано, что содержательные особенности представлений о механизмы, способах и приемах организации успешного поведения и критериях успеха, ценностное отношение к успеху побуждают современного человека к действенным трансформациям (Головина, 2018). В качестве основных векторов исследования психологии успеха сегодня выделяются такие, как: структура компетентного успешного поведения в сложных ситуациях; психологическая дифференциация и компоненты успеха; позитивные и негативные проекции успешности на разных этапах социализации; психологические барьеры реадизации мотивации достижений. В работе Т. Н. Щербаковой доказывается правомерность предположения наличия четкой связи: успешность - социальный интелиект - аутопсихологическая компетентность субъекта - конструктивность действий - стремление к прогрессивным изменениям (Shcherbakova, Loboda, Misirov, 2019).

В проектировании и реализации успешного сценария жизнедеятельности развивающейся дичности имеет большое значение ряд позиций: креативность и критичность мышления, устойчивая дичностная позиция, интегрированность субъективного контроля, готовность осуществлять инновационную активность в условиях повышенной динамичности среды (Тихонова, 2018).

В современных психологических работах показано, что представления личности о будущем успехе актуализирует переживания азарта и удовлетворения, позитивные эмоции, радость; вызывает творческий подъем; активизирует целеустремленные действия, что, в свою очередь, способствует достижению поставленных целей и желаемых результатов.

На уровне современных эмпирических психологических исследований показано наличие корреляции содержания представлений с характером устремлений социализирующегося субъекта и качества активности, за счет реализации основных функций представлений. Интерес представляет тот факт, что, в случае, когда в представлении субъекта его активность ассоциируется с удоводьствием, он стремится конкретизировать и расширить, углубить данное представление.

Социальные представления о престижности для молодого человека успеха, установка на рост и достижения порождают высокий уровень притязаний, определенный тип «дичности достигающей», с ярко выраженной мотивацией 
ПСИХОЛОГИЯ

достижений, ориентацией на самоэффективность в деятельности и общении.

Ресурсность изучения содержания и структуры субъективных представлений об успешности связана с возможностью создания адресных программ оптимизации социализации дичности на этапе студенчества.

Исследования современных психологов убедительно демонстрируют связь уровня успешности личности будущего специалиста с выраженностью стремления к конструктивным трансформациям и саморазвитию. Совершая поступки под воздействием представлений о будущих достижениях субъективно важного результата, студент оказывается более продуктивен и результативен, как в учебно-профессионадьной деятельности, так и в социальном взаимодействии (Козырева, 2018).

В целом, результаты психологических исследований позволяют сделать вывод о значимом вдиянии на содержание представдений, касающихся семантики образа успешной дичности таких индивидуально-психологических особенностей студентов, как наличие индивидуального опыта успешности в дичностно-значимых ситуациях, валентность Я-концепции, характер самоотношения, идентификация с группой успешных людей (Непогодина, Ярушева, 2020).

В студенческом возрасте в развитии представлений об успехе и алгоритмах его достижения участвуют самосознание, личностная рефлексия, самоотношение, знания, самоанадиз опыта. информированность о психодогических барьерах на пути к успеху и аутопсихологическая компетентность дичности.

\section{Методы и методики иссдедования}

В данном исследовании были исподьзованы следующие методы и методики:

1. Анкета «Детерминанты успеха и способы его достижения» (Т. Н. Щербакова, О. Киреев).

2. Тест-опросник «Потребность в достижении» (Ю. М. Орлов, В. И. Шуркин, $И$. П. Орлова).

3. Анализ содержания портфолио студентов.

\section{Результаты}

В ходе проведенного исследования были получены данные, отражающие особенности содержания представлений студентов о детерминантах успеха и способах их достижения.

Анализ полученных результатов демонстрирует, что в представлениях у достаточно большого количества студентов-респондентов (47\%) успех расценивается как достижение выдвигаемых целей и, соответственно, наличие психологически и социально подтвержденного признания в референтном окружении и более широком социуме (41\%). Вместе с тем, только незначительная 
часть студентов (29\%), принявших участие в исследовании утверждают, что достижение успеха связано с переживанием благополучия, позитива, чувства удовлетворенности в профессиональной и дичной жизни. Определенная часть респондентов считает, что успех - это, прежде всего построение карьеры и высокий материальный уровень жизни (39\%). Анализ содержания представлений студентов с разным уровнем успешности социализации в вузе показало, что у студентов с высокими показателями портфолио характеризуются большей степенью определенности и конкретности для них свойственно наличие более четкой структуры и разнообразие содержательных компонентов.

Из числа респондентов, достигших хороших результатов социализации в вузе $57 \%$ отмечают, что достижению успеха способствуют компетентность и мотивация успеха. Высокий процент респондентов (63\%) подчеркивают, что характеристики дичности студента способствуют или препятствуют достижению успеха в зависимости от конкретной ситуации: коммуникабельность иди сдержанность, творчество или умение следовать правилам; склонность к риску или осторожность. Представления об успехе студентов с более интересным портфодио отличаются четкостью и наличием описания разных детерминант успеха. Анализ полученных данных показал, что для студентов с достаточно свернутым портфолио характерны фрагментарность и общий характер представлений о переменных, выступающих в качестве детерминант успеха (рис. 1).

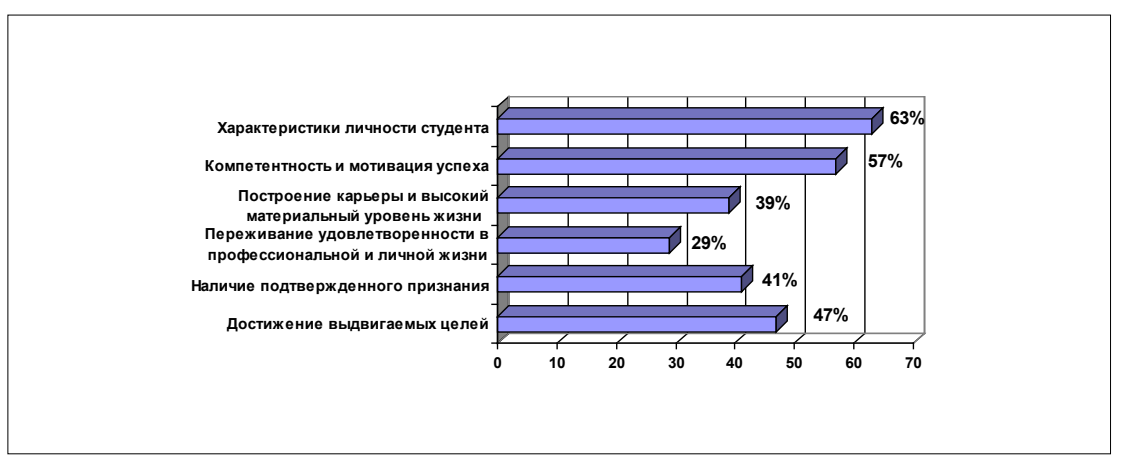

Рисунок 1. Аетерминанты успеха и способы его Аостижения.

Среди компонентов системы мотивационных побуждений достижения профессионального и социального успеха на первом месте оказалось «стремление завоевать лидерство, авторитет, уважение»; далее «требования современного стандарта жизни»; «возможность реализовать свои проекты и идеи»; «стать хозяином жизни»; «желание уметь решать проблемы»; «быть мастером общения»; «обогащение возможностей», «интересная жизнь» (рис. 2). 


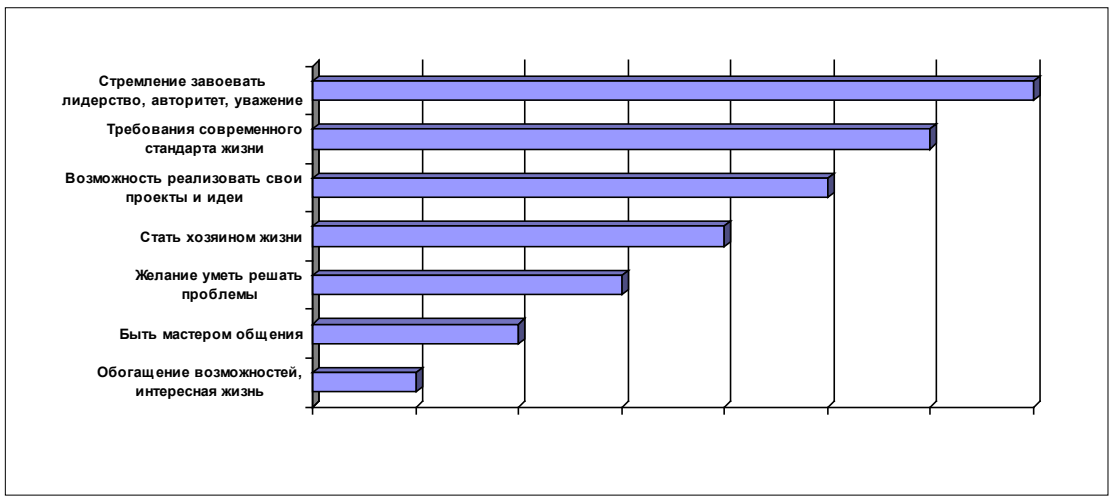

Рисунок 2. Рейтинг системы мотивационных побужАений Аостижения просрессионального и социального успеха.

Совокупность внутренних факторов, вдияющих на успех личности, выделенных респондентами-студентами с более высоким уровнем социализации в вузе и мотивированных на достижения, можно представить в виде схемы (рис. 3).

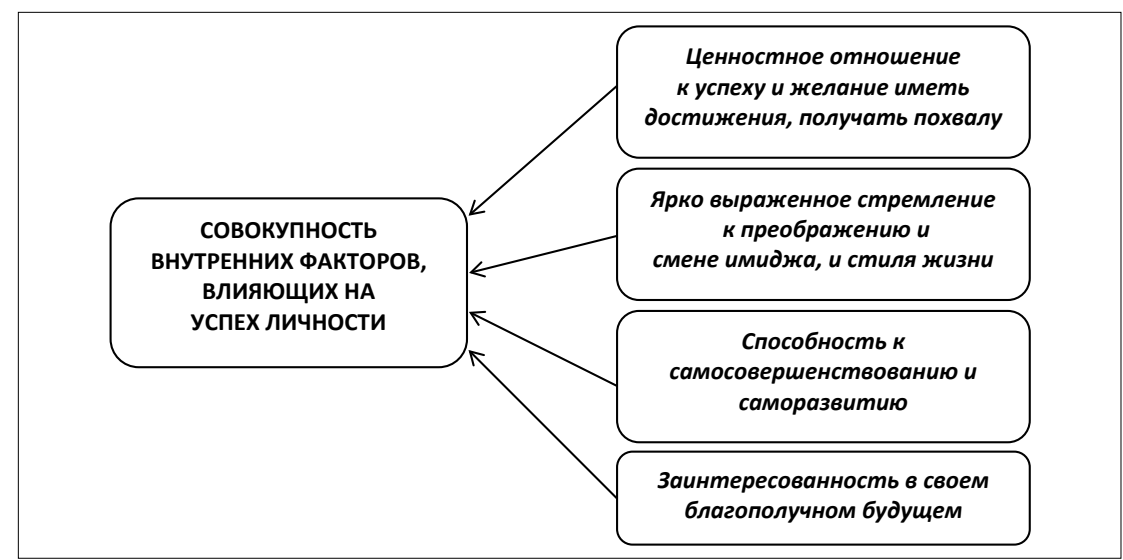

Рисунок 3. Совокупность внутренних фракторов, влияющих на успех ^ичности.

Результаты диагностики показывают, что студенты, имеющие информативное, доказательное портфолио продемонстрировала в большинстве повышенный и высокий уровень выраженности потребности в достижениях (53,2\%), средний уровень $42,8 \%$, а 4 \% имеют пониженный уровень сформированности данной потребности (рис. 4). 


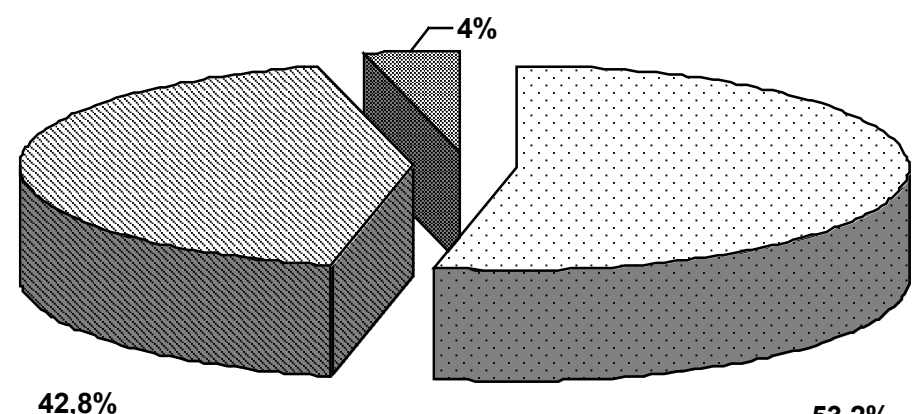

$42,8 \%$

$53,2 \%$

Рисунок 4. Уровень выраженности потребности в Аостижениях на основании анализа солержания порторолио стулентов.

\section{Обсуждение резудьтатов}

В студенческом возрасте возрастает кодичество контактов, активно ведется поиск референтной группы, открываются новые личные горизонты достижений, что также вдияет на содержание представлений об успехе и выбор эффективных моделей социализации. В данном контексте характеристики содержания представлений студентов явдяются отражением определенных возрастных особенностей. Оказывается, что респонденты с более интересным портфолио, демонстрируют более выраженной устремление к достижениям высокого результата, ответственность и заинтересованность в освоении способов достижения успеха в учебно-профессиональной деятельности и социальной жизни. Данная группа студентов чаще проявляет инициативу, демонстрируют готовность решать новые задачи как самостоятельно, так и в команде, одновременно, они ориентированы на признание от социальных зеркал, обладают высокой самооценкой и амбициозностью, могут компетентно отстаивать свои интересы. 3десь находит отражение современный стандарт имиджа мододого человека и система ценностных ориентаций молодежи.

Важно понимание не только содержания успеха, но и способов, алгоритмов его достижения и последствий переживания состояния успешности для развития дичности. Самооценка и самоотношение студентов с разными по уровню содержательности портфодио отличаются также как и степень выраженности потребности в достижениях. Благодаря особенностям возраста студент более восприимчив к новым веяниям, инновациям, вызовам современности. При этом, на данном возрастном этапе, субъект проявляет больше уверенности в собственных перспективах, устремленность к самосовершенствованию и нацеленность 
ПСИХОЛОГИЯ

на формирование престижного имиджа. Решение этих задач, во многом определяется состоятельностью представлений об эффективных моделях успешной активности. Собственно, они составляют индивидуальную платформу выстраивания динии поведения, целью которого является достижение успеха в той или иной сфере. Будущие специалисты сегодня ориентированы не столько на получение диплома о высшем образовании, а на получение престижного места приложения компетентности, возможность личностного роста, возможность заявить свой собственный проект, добиться повышения качества жизни, реализовать жизненный и карьерный успех.

\section{Закдючение}

Значение содержательных адекватных представлений об успехе для социадизации современных студентов определяется, прежде всего тем, что именно на этом этапе активно идет формирование модели будущей социальной и профессиональной активности, индивидуальной траектории развития личности в социальном и профессиональном контексте. Портфодио выступает объективизацией для студента оценки экспертами его возможностей в системе раздичных социальных контекстов. Сегодня портфодио студента является объективным показателем его достижений, его успешности как субъекта учебно-профессиональной деятельности и члена социума в реальной динамике образовательного процесса вуза.

Содержание представлений студентов не только вдияет на характер активности по достижению успеха и ее продуктивность, но и определяет специфику траектории продвижения к более высоким уровням индивидуальных достижений. В содержании представлений студентов делается акцент на таких факторах достижения успеха как креативность, выдержка, коммуникабельность, жизнестойкость, конструктивность и мобильность. Анализ полученных в результате исследования данных дает возможность разрабатывать адресные программы психологического обеспечения оптимизации адаптации студентов в современных условиях неопределенности. Содержательная наполненность подобной программы связана с использованием интегративных технологий актуализации мотивации компетентности и роста, развития способности моделировать продуктивные сценарии будущего.

\section{Автор заявляет об отсутствии конфликта интересов.}

\section{Питература}

Абакумова, И. В., Кагермазова, И. Ц. (2008). Смысловые коммуникации в учебном процессе: теория и технологии направленной трансляциии смыслов в обучении: Монография. Нальчик: Издательство М. и В. Котляровых. 
Асмодов, А. Г., Шехтер, Е. Д., Черноризов, А. М. (2017). Преадаптация к неопределенности как стратегия навигации развивающихся систем: маршруты эводюции. Вопросы психологии, 4, 3-26.

Головина, С. Г. (2018). Отношение к успеху и мотивация успешности студенческой молодежи. Тенденциии развития науки и образования, 43-3, 69-72.

Дубровина, С. В., Домитрак, Е. С., Фирсова, А. В. (2020). Взаимосвязь мотивации достижения успеха с дичностной и ситуативной тревожностью у студентов медицинского вуза. В Философия здоровья: интегральный подход. Межвузовский сборник научных трудов (С. 57-63). Иркутск: Иркутский Государственный Медицинский Университет Министерства Здравоохранения Российской Федерации.

Звездина, Г. П. (2015). Инициация исследовательской активности студентов посредством участия в НИР. В Субъект профессиональной деятельности: стратегии развития и риски. Материалы Международной научно-практической конференции (С. 54-58). Ростов-на-Дону: Донской Государственный Технический Университет.

Звонова, Е. В., Мельников, М. А. (2020). Характеристики мотивации достижения успеха для студентов-участников международных программ. Международный научно-исследовательский журнал, 9-2 (99), 191-195.

Зинченко, Ю. П., Дорожкин, Е. М., Зеер, Э. Ф. (2020). Психологопедагогические основания прогнозирования будущего профессионального образования: векторы развития. Образование и наука, 22(3), 11-35. doi: https:// doi.org/10.17853/1994-5639-2020-3-11-35

Козырева, А. В. (2018). Представления студентов об успехе и успешном человеке. В Инновации в науке и практике. Сборник статей по материалам VIII международной научно-практической конференции. В 5-ти частях (С. 187-198). Барнаул.

Непогодина, А. В., Ярушева, С. А. (2020). Уровень самооценки как фактор успеха профессиональной деятельности. В Управление, әкономика и общество 2020: проблемь и пути развития. Сборник статей участников Международной научно-практической конференции (С. 118-120). Челябинск.

Никоненко, Н. В. (2018). Взаимосвязь эго-состояния дичности и мотивации успеха. Мир педагогики и психологии, 1(18), 107-112.

Петровский, В. А. (2018). Импликативная модель цеелеполагания: константы адаптивного действия. М.: Издательский дом ЯСК.

Соколович, Е. А. (2020). Мотивация достижения успеха и мотивация избегания неудач у индивидов с разными уровнями и видами перфекционизма в период ранней взрослости. Право. Экономика. Психология, 3(19), 105-109.

Тихонова, Н. Е. (2018). Факторы жизненного успеха и социального статуса в сознании россиян. Вестник Института социологии, 9(4(27)), 11-43. 
ПСИХОЛОГИЯ

Abakumova, I., Zvezdina, G., Grishina, A., Zvezdina, E., Dyakova, E. (2020). Student Attitudes Towards Online Education during the COVID-19 Viral Outbreak of 2020: Distance Learning in a Time of Social Distance September 2020. International Journal of Technology in Education and Science, 4(4), 256-266. doi: https://doi. org/10.46328/ijtes.v4i4.107

Shcherbakova, T. N., Loboda, T. V., Misirov, D. N. (2019). Psychological determinants of professional and personal students growth: resources and development risks. In Trends in the Development of Psycho-Pedagogical Education in the Conditions of Transitional Society (ICTDPP-2019). SHS Web of Conferences, 70, 01015. doi: https:// doi.org/10.1051/shsconf/20197001015

Shcherbakova, T., Misirov D., Akobyan M., Zhitnaya I. (2019). Psychological aspects of security culture development for modern students. In International Scientific Conference: "Achievements and Perspectives of Philosophical Studies" (APPSCONF-2019). Web of Conferences, 72, 03010. doi: https://doi.org/10.1051/shsconf/20197203010

\section{References}

Abakumova, I. V., \& Kagermazova, L. C. (2008). Meaning communications in the educational process: theory and technologies of directed translation of meanings in teaching (Monograph). Nalchik: Publishing house of M. and V. Kotlyarov. (in Russ.).

Abakumova, I., Zvezdina, G., Grishina, A., Zvezdina, E., Dyakova, E. (2020). Student Attitudes Towards Online Education during the COVID-19 Viral Outbreak of 2020: Distance Learning in a Time of Social Distance September 2020. International Journal of Technology in Education and Science, 4(4), 256-266. doi: https://doi. org/10.46328/ijtes.v4i4.107 (in Russ.).

Asmolov, A. G., SHekhter, E. D., CHernorizov, A. M. (2017). Pre-adaptation to uncertainty as a navigation strategy for developing systems: the routes of evolution. Psychology issues, 4, 3-26. (in Russ.).

Dubrovina, S. V., Domitrak, E. S., Firsova, A. V. (2020). The relationship of motivation to achieve success with personal and situational anxiety among medical students. In Health Philosophy: An Integral Approach. Interuniversity collection of scientific papers (P. 57-63). Irkutsk: Irkutsk State Medical University of the Ministry of Health of the Russian Federation. (in Russ.).

Golovina, S. G. (2018). Attitude towards success and motivation for success of student youth. Trends in the development of science and education, 43-3, 69-72. (in Russ.).

Kozyreva, A. V. (2018). Students' ideas about success and a successful person. In Innovation in science and practice. Collection of articles based on the materials of the VIII international scientific and practical conference. In 5 parts (P. 187-198). Barnaul. (in Russ.).

Nepogodina, A. V., YArusheva, S. A. (2020). Self-esteem as a factor in professional success. In Management, Economy and Society - 2020: Problems and Ways 
of Development. Collection of articles of the International Scientific and Practical Conference (P. 118-120). Chelyabinsk. (in Russ.).

Nikonenko, N. V. (2018). The relationship between the ego state of the individual and the motivation for success. The world of pedagogy and psychology, 1(18), 107-112. (in Russ.).

Petrovskij, V. A. (2018). Implicative model of goal-setting: the constants of adaptive action. Moscow: Publishing house YASK. (in Russ.).

Shcherbakova, T., Misirov D., Akobyan M., Zhitnaya I. (2019). Psychological aspects of security culture development for modern students. In International Scientific Conference: "Achievements and Perspectives of Philosophical Studies" (APPSCONF-2019). Web of Conferences, 72, 03010. doi: https://doi.org/10.1051/shsconf/20197203010 (in Russ.).

Shcherbakova, T. N., Loboda, T. V., Misirov, D. N. (2019). Psychological determinants of professional and personal students growth: resources and development risks. In Trends in the Development of Psycho-Pedagogical Education in the Conditions of Transitional Society (ICTDPP-2019). SHS Web of Conferences, 70, 01015. doi: https:// doi.org/10.1051/shsconf/20197001015 (in Russ.).

Sokolovich, E. A. (2020). Motivation for achieving success and motivation for avoiding failure in individuals with different levels and types of perfectionism in early adulthood. Pravo. Ekonomika. Psikhologiya, 3(19), 105-109. (in Russ.).

Tihonova, N. E. (2018). Factors of success in life and social status in the minds of Russians. Vestnik of Institute of Sociology, 9(4(27)), 11-43. (in Russ.).

Zinchenko, YU. P., Dorozhkin, E. M., Zeer, E. F. (2020). Psychological and pedagogical foundations of forecasting future professional education: vectors of development. Education and Science, 22(3), 11-35. doi: https://doi.org/10.17853/19945639-2020-3-11-35 (in Russ.).

Zvezdina, G. P. (2015). Initiation of research activity of students through participation in research work. In The subject of professional activity: development strategies and risks. Proceedings of the International Scientific and Practical Conference (P. 54-58). Rostov-on-Don: Don State Technical University. (in Russ.).

Zvonova, E. V., Mel'nikov, M. A. (2020). Characteristics of motivation for achieving success for students participating in international programs. International research journal, 9-2 (99), 191-195. (in Russ.). 